\title{
PENGARUH STRATEGI PEMASARAN DAN KUALITAS PELAYANAN TERHADAP KEPUTUSAN PEMBELIAN KONSUMEN DI PT SARANA BANDAR LOGISTIK
}

\author{
Febri Indra Prabowo ${ }^{1}$, Yulianti Keke ${ }^{2 *}$, Bambang Istidjab ${ }^{3}$ \\ ${ }^{1,2,3}$ Program Studi Manajemen, Fakultas Manajemen dan Bisnis \\ Institut Transportasi Logistik Trisakti, Jakarta, Indonesia \\ * Penulis korespondensi; Email: yuliakeke@gmail.com
}

\begin{abstract}
Abstrak: Perkembangan perusahaan pelayaran dalam bidang pengangkutan dan penanganan muatan dari waktu ke waktu semakin menjadi kepedulian konsumen. PT Sarana Bandar Logistik, anak perusahaan PT Pelayaran Nasional Indonesia (PELNI) yang melaksanakan kegiatan logistik tranportasi laut di negara kita, diharuskan mengembangkan kualitas pelayanan kepada konsumen dengan menaikan kualitas kerja masing-masing bidang dengan melaksanakan sistem, metode atau yang sudah di atur pada kegiatan bongkar muat di pelabuhan. Hasil penelitian ini adalah terdapat pengaruh yang siginifikan dari variabel Strategi Pemasaran dan Kualitas Pelayanan terhadap Keputusan Pembelian dengan kontribusi sebesar 59,3\%, dan 40,7\% merupakan pengaruh dari faktor lain. Berdasarkan hasil analisis dan pembahasan penulis menyimpulkan bahwa strategi pemasaran dan kualitas pelayanan secara bersama berpengaruh positif dan signifikan pada keputusan pembelian konsumen pada PT Sarana Bandar Logistik.
\end{abstract}

Kata kunci: Strategi Pemasaran, Kualitas Pelayanan, Keputusan Pembelian Konsumen.

\begin{abstract}
The development of shipping companies in the field of transportation and handling of cargo from year to year is increasingly becoming the public's attention. PT Sarana Bandar Logistik, a subsidiary of PT Pelayaran Nasional Indonesia (PELNI), which carries out sea transportation logistics activities throughout Indonesia, is required to improve the quality of service to the community by increasing the work performance of each by implementing systems, methods or standardization in loading and unloading activities at the port. The results of this study are that there is a significant influence of the variables of Marketing Strategy and Service Quality on Purchase Decisions with a contribution of 59.3\%, and $40.7 \%$ is the influence of other factors. Based on the results of the analysis and discussion, it can be concluded that the marketing strategy and service quality together have a positive and significant effect on consumer purchasing decisions at PT Sarana Bandar Logistik.
\end{abstract}

Keywords: Marketing Strategy, Service Quality, Consumer Purchasing Decisions.

\section{PENDAHULUAN}

PT Sarana Bandar Logistik anak perusahaan PT PELNI adalah perusahaan lokal yang melaksanakan dibagian angkutan multimoda yang berlokasi di Indonesia dan menerima layanan pengiriman logistik. Sebagai perusahaan multimoda, PT Sarana Bandar Logistik menggabungkan beberapa moda transportasi untuk layanan pengiriman barang. Perkembangan perusahaan pelayaran dalam bidang pengangkutan dan penanganan barang dari waktu ke waktu semakin menjadi kepedulian konsumen, hal ini bisa diteliti dari tingginya persaingan produk jasa, harga, promosi, lokasi dan kualitas pelayanan. Dengan perusahaan lain yang juga semakin bagus, hal yang harus diutamakan oleh perusahaan jasa pelayaran adalah memaksimalkan strategi pemasaran dan meningkatkan kualitas pelayanan agar dapat bersaing dan menguasai pangsa pasar. Sehingga pelayanan dan pemasaran harus dikelola secara optimal untuk menjadi senjata perusahaan dalam menarik minat konsumen namun pada kenyataannya masih banyak permasalahan yang menjadi hambatan dalam pelayanan dan pemasaran yang berdampak pada tingkat keputusan pembelian konsumen seperti masih kurang ramahnya pelayanan yang diberikan karyawan terhadap konsumennya, kurang aktifnya media sosial dan website untuk mengupdate informasi jadwal kapal dan ketersediaan kapasitas muatan di dalam kapal atau slot yang masih tersedia, kurangnya iklan di media internet sehingga belum banyaknya individu maupun perusahaan yang mengetahui pelayanan apakah yang ditawarkan perusahaan ini, jarangnya perusahaan melakukan promosi potongan harga sehingga promosi yang dilakukan perusahaan belum optimal dalam menarik minat konsumen untuk menggunakan perusahaan ini, kantor penerimaan barang yang hanya ada di Tanjung Priok saja sehingga menyulitkan konsumen yang berada di daerah penyangga Kota Jakarta seperti Bekasi, Bogor, Depok, Tangerang jika ingin mengirimkan barangnya.

Dalam penelitian ini terdapat penelitian terdahulu yang relevan diantaranya: (1) Harahap (2018) yang meneliti tentang Pengaruh Strategi Pemasaran terhadap Keputusan Pembelian Asuransi Kendaraan 
Bermotor pada PT Asuransi Sinarmas Cabang Garut yang mengguakan metode kuantitatif sementara hasil penelitian yang didapat yaitu pengaruh secara parsial dimana peneliti membedakan besaran nilai t hitung dengan $t$ tabel untuk pengujian secara parsial, sehingga diperoleh hasil bahwa strategi pemasaran berpengaruh terhadap keputusan pembelian asuransi kendaraan bermotor pada PT Asuransi Sinarmas Cabang Garut, (2) Amhar (2012) yang meneliti tentang Pengaruh kompetensi financial advisor dan kualitas layanan bank terhadap keputusan pembelian barang produk bancassurance pada PT AXA Mandiri Finansial Service yang menggunakan metode kuantitatif dari hasil penelitian terdapat pengaruh positif yang signifikan antara kualitas layanan terhadap keputusan pembelian produk bancassurance dan (3) Kuswaraningtyas (2017) yang meneliti tentang Pengaruh Produk Harga, Promosi, Tempat dan Kualitas Pelayanan Terhadap Keputusan Pembelian Pada Konsumen PT Jalur Nugraha Ekakurir yang menggunakan metode kuantitatif dan hasil penelitian menunjukan secara simultan dan parsial Produk, Harga, Lokasi, Promosi dan Kualitas Pelayananber pengaruh positif dan signifikan terhadap Keputusan Pembelian pada konsumen PT Jalur Nugraha Ekakurir.

\section{TINJAUAN TEORI}

Menurut Sunyoto (2015), strategi pemasaran adalah teknik yang akan dipakai oleh sebuah perusahaan untuk bisa meraih tujuan yang sudah direncanakan sebelumnya, diisinya terdapat putusan-putusan inti tentang target pasar, penempatan produk di pasar, bauran pemasaran dan nilai biaya pemasaran yang dibutuhkan. Menurut Assauri (2013) strategi pemasaran ialah salah satu target dan keinginan, aturan dan standar sebagai pedoman untuk upaya dalam memasarkan produk atau jasa dari masa ke masa, dalam tiap tingkatan dan target serta rinciannya, pada intinya untuk menanggapi perusuhaan untuk beradaptasi dilingkungan dan situasi persaingan yang tidak pasti. Menurut Tjiptono (2010), strategi pemasaran yaitu alat perusahaan yang dilakukan untuk meraih target perusahaan dengan memaksimalkan potensi bersaing yang beriringan melalui pasar yang ingin dituju dan strategi pemasaran yang dipakai untuk menyanggupi pasar tujuan tersebut. Menurut Hurriyati (2010), masing-masing perusahaan selalu bekerja keras agar dapat terus berkembang, dan terus dapat bersaing. Bauran pemasaran yaitu rencana strategi yang dilakukan perusahaan, dimana ada 4 unsur, ialah produk, harga, tempat, promosi. Unsur-unsur bauran pemasaran menurut Kotler and Amstrong (2012) adalah: (1) Produk, (2) Harga, (3) Promosi, dan (4) Tempat.
Menurut Majid (2015), keunggulan di dalam bidang layanan jasa yaitu sebuah penyajian produk atau jasa sesuai standar yang ditetapkan dimana produk itu tersedia dan sosialisasinya setidaknya sesuai dengan yang direncanakan dan didambakan oleh konsumen. Menurut Tjiptono (2011) ada beberapa unsur yang memengaruhi sebuah layanan yaitu expected service (layanan yang diharapkan) dan perceived service (layanan yang diterima). Jika layanan yang diterima sama bahkan bisa mencapai yang diinginkan maka layanan dapat dikatakan positif atau baik. Jika perceived service melewati expected service, maka kualitas pelayanan diasumsikan sebagai kualitas yang ideal. Juga sebaliknya jika perceived service lebih buruk dibanding expected service, maka kualitas layanan diasumsikan buruk atau negatif. Maka dari itu, bagus atau buruk kualitas layanan bergantung dengan kemampuan perusahaan dan standarnya mampu memenuhi persepsi konsumen secara terusmenerus. Menurut Supranto (2011), kulitas layanan yaitu suatu kata yang menurut perusahaan jasa adalah suatu hal yang mesti dilakukan dengan baik. Implementasi kualitas dalam sebuah standarisasi dari tampilan produk maupun kinerja adalah bagian inti dari strategi perusahaan dalam hal mendapat target yang diinginkan, muali dari pemimpin pasar maupun sebagai fomasi agar terus berkembang. Menurut Tjiptono (2011) ada 5 unsur inti dalam kulitas layanan yaitu: (1) Reabilitas, (2) Daya Tanggap, (3) Jaminan, (4) Empati, dan (5) Bukti Fisik.

Menurut Kotler and Amstrong (2014), keputusan pembelian (purchase decision) konsumen ialah tahap di dalam proses pemilihan keputusan pembelian dimana konsumen serius untuk membeli. Menurut Tjiptono dan Chandra (2012), keputusan pembelian yaitu suatu proses dimana konsumen mengetahui permasalahannya, mencari tahu tentang suatu produk atau merek tertentu dan mengevaluasikan secara baik tiap alternatif itu bisa mncari jalan keluar masalahnya, yang selanjutnya mengarah ke keputusan pembelian. Menurut Schiffman and Kanuk (2014), keputusan pembelian diartikan sebagai suatu pilihan dari dua atau lebih alternatif rencana. Menurut Kotler and Amstrong (2016), "The consumer tipicaly passed through five stage: problem recognition, information search, evaluation of alternative, purchase decision, and post purchase behavior". Berikut yaitu 5 tahapan dalam pengambilan keputusan pembelian menurut Sumarwan (2011): (1) Pengenalan kebutuhan, (2) Pencarian informasi, (3) Evaluasi alternative, (4) Keputusan pembelian, dan (5) Perilaku pasca pembelian. Indikator keputusan pembelian menurut Kotler and Keller (2013) terdapat 6 keputsan pembelian yang dilakukan konsumen, yaitu: (1) Pilihan produk, (2) Pilihan merek, (3) Pilihan penyalur, (4) Waktu pembelian, (5) Jumlah pembelian, dan (6) Metode pembayaran. 
Sementara tujuan penelitian ini untuk mencari tahu strategi pemasaran terhadap keputusan pembelian konsumen, untuk mencari tahu kualitas pelayanan terhadap keputusan pembelian konsumen, dan untuk mencari tahu strategi pemasaran dan kualitas pelayanan terhadap keputusan pembelian konsumen.

Dari uraian-uraian di atas dapat diperjelas melalui variabel pengaruh strategi pemasaran dan kualitas pelayanan terhadap keputusan pembelian konsumen, berdasarkan uraian di atas maka penulis membuat konsentrasi variabel penelitian. Berikut ini kerangka konseptual penelitian ini:

$\mathrm{X}_{1}$ : Strategi Pemasaran

$\mathrm{X}_{2}$ : Kualitas Pelayanan

Y : Keputusan Pembelian Konsumen

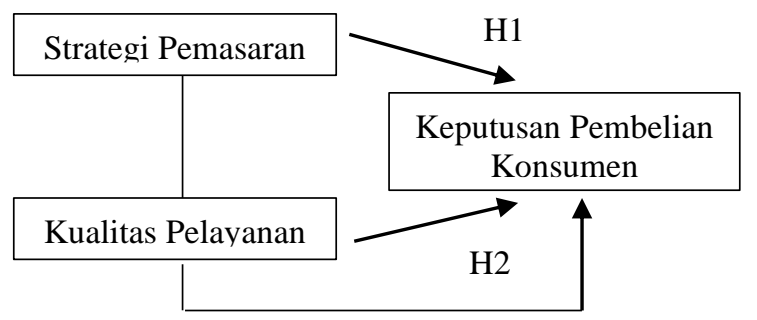

Gambar 1. Kerangka Teori

Berdasarkan kerangka pemikiran di atas, maka peneliti membuat hipotesis Assosiatif (hubungan) yang diuji yaitu:

H1: Diduga terdapat pengaruh positif diantara variabel strategi pemasaran terhadap variabel Keputusan Pembelian Konsumen

H2: Diduga terdapat pengaruh positif diantara variabel kualitas pelayanan terhadap variabel Keputusan Pembelian Konsumen

H3: Diduga terdapat pengaruh positif diantara variabel strategi pemasaran dan kualitas pelayanan terhadap variabel Keputusan Pembelian Konsumen

\section{METODE PENELITIAN}

Penelitian ini untuk menganalisis tentang pengaruh strategi pemasaran dan kualitas pelayanan terhadap keputusan pembelian konsumen Periode Desember Tahun 2019 - Februari Tahun 2020. Observasi yang dipilih yaitu dengan kuesioner yang akan serahkan ataupun diberika ke objek penelitian, ialah konsumen PT Sarana Bandar Logistik di Pelabuhan Tanjung Priok Kota Jakarta Utara.

Populasi penelitian ini yaitu pengguna jasa pada PT Sarana Bandar Logistik yang berjumlah 49 orang. Teknik pengambilan sampel yang dilakukan yaitu Non Probability Sampling dengan penggunaan Sampel Jenuh. Menurut Sugiyono (2017), sampel jenuh yaitu cara pengambilan sampel apabila semua anggota populasi digunakan sebagai sampel. Sampel yang digunakan yaitu seluruh anggota populasi sebanyak 49 orang.

Instrumen penelitian ialah sebuah alat yang dipakai untuk mengukur fenomena alam ataupun sosial yang diteliti (Sugiyono, 2017). Instrumen di dalam penelitian ini dirangkai berlandaskan indikator yang terdapat didalam kualitas pelayanan, strategi pemasaran dan keputusan pembelian konsumen selanjutnya dijelaskan didalam butir-butir pertanyaan.

\section{HASIL DAN PEMBAHASAN}

Agar mengetahui adanya pengaruh antara variabel Strategi Pemasaran $\left(\mathrm{X}_{1}\right)$ dan variabel Kualitas Pelayanan $\left(\mathrm{X}_{2}\right)$ terhadap Keputusan Pembelian Konsumen $(\mathrm{Y})$, maka penulis menggunakan analisis kuantitatif yang menggunakan perhitungan statistik metode koefisien korelasi berganda, regresi linear berganda, uji hipotesis dan koefisien determinasi. Dimana data-data yang jadi acuan didapat dari hasil kuesioner yang dibagikan ke konsumen pada PT Sarana Bandar Logistik Cabang Tanjung Priok dan diolah dalam bentuk perhitungan.

\section{Analisis Koefisien Korelasi}

Agar menemukan pengaruh variabel independen terhadap variabel dependen, oleh karena itu penulis menggunakan analisis korelasi antara variabel penelitian secara individual dimana hasilnya yang bisa dilihat pada Tabel 1 melalui hitungan SPSS.

Tabel 1. Analisis Koefisien Korelasi

\begin{tabular}{lcccccc}
\hline \multicolumn{7}{c}{ Coefficients $^{\mathbf{a}}$} \\
\multicolumn{1}{c}{ Model } & $\begin{array}{c}\text { Unstandardized } \\
\text { Coefficients }\end{array}$ & $\begin{array}{c}\text { Std. } \\
\text { Coefficients }\end{array}$ & & \\
\cline { 2 - 4 } & Beta & $\begin{array}{c}\text { Std. } \\
\text { Error }\end{array}$ & Beta & & Sig. \\
\hline (Constant) & 6.883 & 4.441 & & 1.550 & 0.128 \\
$\begin{array}{l}\text { Strategi } \\
\text { Pemasaran }\end{array}$ & 0.517 & 0.121 & 0.485 & 4.281 & 0.003 \\
$\begin{array}{l}\text { Kualitas } \\
\text { Pelayanan }\end{array}$ & 0.323 & 0.095 & 0.385 & 3.396 & 0.001 \\
\hline $\begin{array}{l}\text { a. Dependent Variable: Keputusan Pembelian Konsumen } \\
\text { Sumber: Diolah oleh Penulis menggunakan IBM SPSS versi 26 }\end{array}$
\end{tabular}

Dari Tabel 1 tersebut bisa dilihat bahwa nilai koefisien korelasi antara Strategi Pemasaran $\left(\mathrm{X}_{1}\right)$ dengan Keputusan Pembelian Konsumen (Y) sebesar perhitungan korelasi sederhana diperoleh 0,701. Dimana menunjukan pengaruh yang begitu kuat dan ada di interval $(0,600-0,799)$, selanjutnya nilai koefisien korelasi diantara Kualitas Pelayanan $\left(\mathrm{X}_{2}\right)$ dengan Keputusan Pembelian Konsumen (Y) senilai 0,656 yang menunjukan pengaruh yang begitu kuat ada di interval $(0,600-0,799)$. 
Berlandaskan kedua koefisien korelasi tersebut ternyata kedua variabel memiliki pengaruh yang kuat pada taraf nyata (alpha) jauh dibawah 5\% $(0,05)$ yaitu Kualitas Pelayanan $(0,000)$ dan Kualitas Pelayanan $(0,000)$.

\section{Analisis Regresi Linier Berganda}

Dilakukan agar dapat mencari tahu besarnya pengaruh variabel pengaruh Strategi Pemasaran $\left(\mathrm{X}_{1}\right)$ dan Kualitas Pelayanan $\left(\mathrm{X}_{2}\right)$ secara parsial maupun simultan terhadap Keputusan Pembelian Konsumen (Y). Hitungan statistik didalam analisis regresi linier berganda secara lengkap dapat dilihat pada Tabel 2.

Tabel 2. Analisis Regresi Linier Berganda

\begin{tabular}{|c|c|c|c|c|}
\hline \multicolumn{5}{|c|}{$\begin{array}{lc}\text { Correlations } \\
\end{array}$} \\
\hline & & $\begin{array}{c}\text { Strategi } \\
\text { Pemasaran }\end{array}$ & $\begin{array}{c}\text { Kualitas } \\
\text { Pelayanan }\end{array}$ & $\begin{array}{l}\text { Keputusan } \\
\text { Pembelian } \\
\text { Konsumen }\end{array}$ \\
\hline \multirow{3}{*}{$\begin{array}{l}\text { Strategi } \\
\text { Pemasaran }\end{array}$} & $\begin{array}{l}\text { Pearson } \\
\text { Correlation }\end{array}$ & 1 & $.559 * *$ & $.701 * *$ \\
\hline & Sig. (2-tailed) & & 0,000 & 0,000 \\
\hline & $\mathrm{N}$ & 49 & 49 & 49 \\
\hline \multirow{3}{*}{$\begin{array}{l}\text { Kualitas } \\
\text { Pelayanan }\end{array}$} & $\begin{array}{l}\text { Pearson } \\
\text { Correlation }\end{array}$ & $.559 * *$ & 1 & $.656^{* *}$ \\
\hline & Sig. (2-tailed) & 0,000 & & 0,000 \\
\hline & $\mathrm{N}$ & 49 & 49 & 49 \\
\hline \multirow{3}{*}{$\begin{array}{l}\text { Keputusan } \\
\text { Pembelian } \\
\text { Konsumen }\end{array}$} & $\begin{array}{l}\text { Pearson } \\
\text { Correlation }\end{array}$ & $.701 * *$ & $.656^{* *}$ & 1 \\
\hline & Sig. (2-tailed) & 0,000 & 0,000 & \\
\hline & $\mathrm{N}$ & 49 & 49 & 49 \\
\hline
\end{tabular}

** Correlation is significant at the 0.01 level (2-tailed).

Sumber: Diolah oleh Penulis menggunakan IBM SPSS versi 26

Model persamaan regresi yang bisa dijelaskan di hasil tersebut pada bentuk persamaan regresi berikut:

$\mathrm{Y}=6,883+0,517 \mathrm{X}_{1}+0,323 \mathrm{X}_{2}$

Keterangan:

a) Nilai Konstanta $\mathrm{a}=6,883$ dapat diartikan bahwa bila variabel bebas dihiraukan atau kata lain bila tidak terdapat variabel pada pengaruh Strategi Pemasaran dan Kualitas Pelayanan, bila Keputusan Pembelian Konsumen pada PT Sarana Bandar Logistik Cabang Tg. Priok akan bernilai 6,883.

b) Nilai Koefisien $b_{1}=0,517$ ini berarti jika setiap perubahan satu-satuan pada pengaruh Strategi Pemasaran dalam dengan asumsi Kualitas Pelayanan, maka Keputusan Pembelian Konsumen pada PT Sarana Bandar Logistik Cabang Tg. Priok maka akan terjadi kenaikan senilai 0,517 dan berubah ke arah yang sama.

c) Nilai Koefisien $b_{2}=0,323$ ini berarti jika tiap perubahan satu-satuan pada Kualitas Pelayanan dengan perkiraan Strategi Pemasaran, maka Keputusan Pembelian Konsumen pada PT Sarana Bandar Logistik Cabang Tg. Priok maka akan terjadi kenaikan senilai $=0,323$ dan berubah ke arah yang sama.

\section{Uji Hipotesis}

\section{Uji T}

Uji T dilakukan agar dapat mengetahui pengaruh secara parsial variabel independen (X) terhadap dependen (Y). Berikut ini akan dijelaskan pengujian masing-masing variabel secara parsial.

Tabel 3. Analisis Regresi Antara Variabel $X_{1}+X_{2}=Y$

\begin{tabular}{lccccc}
\multicolumn{7}{c}{ Coefficients $^{\mathrm{a}}$} \\
\hline \multirow{2}{*}{ Model } & \multicolumn{2}{c}{$\begin{array}{l}\text { Unstandardized } \\
\text { Coefficients }\end{array}$} & $\begin{array}{c}\text { Std. } \\
\text { Coefficients }\end{array}$ & $\mathrm{t}$ & Sig. \\
\cline { 2 - 5 } & Beta & $\begin{array}{c}\text { Std. } \\
\text { Error }\end{array}$ & Beta & & \\
\hline (Constant) & 6.883 & 4.441 & & 1.550 & 0.128 \\
\hline $\begin{array}{l}\text { Strategi } \\
\text { Pemasaran }\end{array}$ & 0.517 & 0.121 & 0.485 & 4.281 & 0.003 \\
\hline $\begin{array}{l}\text { Kualitas } \\
\text { Pelayanan }\end{array}$ & 0.323 & 0.095 & 0.385 & 3.396 & 0.001
\end{tabular}

a. Dependent Variable: Keputusan Pembelian Konsumen

Sumber: Diolah oleh Penulis menggunakan IBM SPSS versi 26

Pengaruh Strategi Pemasaran $\left(X_{1}\right)$ terhadap Keputusan Pembelian Konsumen $(Y)$

Dari pengujian secara parsial di Tabel 3 bisa diketahui jika tingkat signifikan pengaruh variabel Strategi Pemasaran $\left(\mathrm{X}_{1}\right)$ terhadap Keputusan Pembelian Konsumen (Y) sebesar 0,003 dan thitung sebesar 4,281. Dan dari jumlah responden (n) yaitu sebanyak 49 orang maka dapat diperoleh sebesar 2,012 dan dapat diperoleh dari rumus:

$$
\begin{aligned}
\mathrm{t}_{\text {tabel }} & =(\alpha / 2 ; \mathrm{n}-\mathrm{k}) \\
& =(0,05 / 2 ; 49-2) \\
& =(0,025 ; 47) \\
& =2,012
\end{aligned}
$$

Dari data tersebut maka diperoleh hasil:

a. 0,003 <0,05, maka berdasarkan hasil di atas Ho ditolak Ha diterima.

b. 4,281 > 2,012, maka dari hasil tersebut Ho ditolak Ha diterima.

Maka demikian hipotesis pertama sudah diketahui, berlandaskan hasil di atas bisa disimpulkan bahwa terjadi pengaruh yang signifikan dan positif diantara pengaruh Strategi Pemasaran terhadap Keputusan Pembelian Konsumen.

\section{Pengaruh Kualitas Pelayanan $\left(X_{2}\right)$ terhadap Keputusan Pembelian Konsumen ( $Y$ )}

Berdasarkan pengujian secara parsial di tabel 4 bisa diketahui jika tingkat signifikan pengaruh variabel Kualitas Pelayanan $\left(\mathrm{X}_{2}\right)$ terhadap Keputusan Pembelian Konsumen (Y) sebesar 0,001 dan thitung sebesar 3,396.

Dari data tersebut maka diperoleh hasil:

a. 0,001 <0,05, maka berdasarkan hasil di atas Ho ditolak Ha diterima.

b. 3,396 > 2,012, maka dari hasil tersebut Ho ditolak Ha diterima. 
Maka demikian hipotesis pertama sudah terbukti berlandaskan hasil di atas, bisa disimpulkan jika terjadi pengaruh yang signifikan dan positif diantara pengaruh Kualitas Pelayanan terhadap Keputusan Pembelian Konsumen.

\section{Uji F}

Uji $F$ dipakai karena untuk mencari tahu ada atau tidak adanya pengaruh secara keduanya ataupun simultan diantara semua variabel yang tidak terikat (Strategi Pemasaran dan Kualitas Pelayanan) dengan variabel terikat (Keputusan Pembelian Konsumen) berikut:

1) Ho: $\rho=0$, artinya bila hasil sig $>0,05$ ataupun $F_{\text {hitung }}<F t_{\text {abel }}$ dapat dikatakan tidak terdapat pengaruh variabel $X_{1}$ dan $X_{2}$ secara simultan pada variabel $\mathrm{Y}$.

2) Ha: $\rho \neq 0$, artinya bila hasil sig $\left\langle 0,05\right.$ atau $\left.F_{\text {hitung }}\right\rangle$ $F_{\text {tabel }}$ dapat dikatakan pengaruh variabel $\mathrm{X}_{1}$ dan $\mathrm{X}_{2}$ secara simultan pada variabel $\mathrm{Y}$.

Tabel 4. Pengaruh Variabel $\mathrm{X}_{1}$ dan $\mathrm{X}_{2}$ Terhadap $\mathrm{Y}$

\begin{tabular}{lccccc}
\multicolumn{7}{c}{ ANOVA $^{\mathbf{a}}$} \\
\hline \multicolumn{1}{c}{ Model } & $\begin{array}{c}\text { Sum of } \\
\text { Squares }\end{array}$ & Df & $\begin{array}{c}\text { Mean } \\
\text { Square }\end{array}$ & F & Sig. \\
\hline Regression & 400.854 & 2 & 200.427 & 33.508 & $\mathbf{. 0 0 0}^{\mathbf{b}}$ \\
Residual & 275.146 & 46 & 5.981 & & \\
Total & 676.000 & 48 & & & \\
\hline
\end{tabular}

a. Dependent Variable: Keputusan Pembelian Konsumen

b. Predictors: (Constant) Strategi Pemasaran, Kualitas Pelayanan

Sumber: Diolah oleh Penulis menggunakan IBM SPSS versi 26

Menetapkan tarif nyata $(\alpha)$ / tingkat keyakinan (1$\alpha)$ untuk mencari $\mathrm{t}_{\alpha}(\alpha)=5 \%$ atau nilai keyakinan $(1-\alpha)$ $=(1-0,05 \%)=0,95 \%$, karena bila semakin tinggi nilai keyakinan juga akan semakin benar hasil yang didapat. Oleh karena itu penulis memilih uji statistik dengan rumus sebagai berikut:

Keterangan:

$$
\begin{aligned}
f_{\text {tabel }} & =(\mathrm{k} ; \mathrm{dk})=(\mathrm{k} ; \mathrm{n}-\mathrm{k}-1) \\
& =(2 ; 49-2-1) \\
& =(2 ; 46) \\
& =3,20 \\
k \quad: & 2, \text { Sebagai Angka Pembilang } \\
d k \quad: & 46, \text { Sebagai Angka Penyebut } \\
F_{\text {Tabel }} & : 3,20
\end{aligned}
$$

Cara mencari $F_{\text {Tabel: }}$ :

a. $0,000<0,05$, maka berdasarkan hasil di atas Ho tidak diterima dan Ha diterima.

b. 33,508 > 3,20, maka dari hasil tersebut Ho tidak diterima dan Ha dapat diterima. Maka dari itu bisa diasumsikan jika Strategi Pemasaran $\left(\mathrm{X}_{1}\right)$ dan Kualitas Pelayanan $\left(\mathrm{X}_{2}\right)$ secara simultan berdampak signifikan dan positif pada Keputusan
Pembelian Konsumen (Y) yaitu senilai 0,000 < 0,05 dan hasil $F_{\text {hitung }}=33,508>F_{\text {tabel }}=3,20$ berlandaskan nilai diatas, dapat dikatakan hipotesis ketiga sudah terbukti.

Bersadarkan uji $f$ tersebut jadi bisa dikatakan jika variabel Strategi Pemasaran $\left(\mathrm{X}_{1}\right)$ dan Kualitas Pelayanan $\left(\mathrm{X}_{2}\right)$ pada variabel Keputusan Pembelian Konsumen (Y) mempunyai korelasi berganda yang positif dan kuat. Dapat diasumsikan hipotesis pertama terjadi korelasi yang positif antara Pengaruh Strategi Pemasaran $\left(\mathrm{X}_{1}\right)$ dan Kualitas Pelayanan $\left(\mathrm{X}_{2}\right)$ pada variabel Keputusan Pembeliam Konsumen (Y) di PT Sarana Bandar Logistik Cabang Tanjung Priok.

\section{Analisis Koefisien Korelasi Berganda}

Koefisien korelasi berganda digunakan guna menemukan seberapa erat pengaruh variabel tidak terikat (Strategi Pemasaran dan Kualitas Pelayanan) pada variabel terikat (Keputusan Pembelian Konsumen) secara simultan, Tabel 5 adalah hitungan dari hasil koefisien korelasi berganda.

Tabel 5. Koefisien Korelasi Berganda

\begin{tabular}{ccccccc}
\hline \multicolumn{7}{c}{ Model Summary } \\
Model & $\mathbf{R}$ & $\begin{array}{c}\text { R } \\
\text { Square }\end{array}$ & $\begin{array}{c}\text { Adjusted R } \\
\text { Square }\end{array}$ & $\begin{array}{c}\text { Std. Error } \\
\text { of the } \\
\text { Estimate }\end{array}$ & $\begin{array}{c}\text { R Square } \\
\text { Change }\end{array}$ & F Change \\
\hline 1 & $.770^{\mathrm{a}}$ & 0.593 & 0.575 & 2.446 & 0.593 & 33.508 \\
\hline
\end{tabular}

a. Predictors: (Constant), Strategi Pemasaran, Kualitas Pelayanan Sumber: Diolah oleh Penulis menggunakan IBM SPSS versi 26

Dari tabel tersebut nilai koefisien korelasi berganda $R=0,770$. Dengan demikian besarnya pengaruh Strategi Pemasaran dan Kualitas Pelayanan pada Keputusan Pembelian Konsumen di PT Sarana Bandar Logistik Cabang Tg. Priok yaitu 0,770 dan ada pada interval $(0,600-0,799)$ dari hasil ini artinya mempunyai pengaruh yang searah, kuat dan positif.

\section{Analisis Koefisien Determinasi}

Tabel 6. Koefisien Determinasi

\begin{tabular}{ccccccc}
\multicolumn{8}{c}{ Model Summary } \\
\hline Model & $\mathbf{R}$ & $\begin{array}{c}\mathbf{R} \\
\text { Square }\end{array}$ & $\begin{array}{c}\text { Adjusted R } \\
\text { Square }\end{array}$ & $\begin{array}{c}\text { Std. Error } \\
\text { of the } \\
\text { Estimate }\end{array}$ & $\begin{array}{c}\text { R Square } \\
\text { Change }\end{array}$ & F Change \\
\hline 1 & $.770^{\mathrm{a}}$ & 0.593 & 0.575 & 2.446 & 0.593 & 33.508 \\
\hline
\end{tabular}

a. Predictors: (Constant), Strategi Pemasaran, Kualitas Pelayanan Sumber: Diolah oleh Penulis menggunakan IBM SPSS versi 26

Koefisien determinasi disini dimaksudkan guna menemukan berapa kuat kontribusi atau perubahan yang diberikan variabel tidak terikat tehadap variabel terikat, didapat melalui cara berikut:

$\mathrm{KD}=\mathrm{R}^{2} \times 100 \%$

Maka,

$\mathrm{KD}=(0,770)^{2} \times 100 \%$

$\mathrm{KD}=0,593 \times 100 \%$

$\mathrm{KD}=59,3 \%$ 
Berdasarkan perhitungan di atas, hasil koefisien determinasi yang disesuaikan atau R Square $=59,3 \%$. Maka nilai kontribusi Pengaruh Strategi Pemasaran $\left(\mathrm{X}_{1}\right)$ dan Kualitas Pelayanan $\left(\mathrm{X}_{2}\right)$ terhadap Keputusan Pembelian Konsumen (Y) di PT. Sarana Bandar Logistik Cabang Tanjung Priok yaitu senilai 59,3\%, dan sisanya 40,7\% merupakan pengaruh dari hal yang lain.

\section{Pembahasan}

\section{Pengaruh Strategi Pemasaran $\left(X_{I}\right)$ terhadap Keputusan Pembelian Konsumen (Y)}

Dari hitungan analisis regresi berganda didapat nilai koefisien $b_{1}$ yaitu 0,517 yang bernilai positif maka bisa diambil kesimpulan variabel Strategi Pemasaran $\left(\mathrm{X}_{1}\right)$ mempunyai pengaruh positif terhadap Keputusan Pembelian Konsumen (Y), jadi jika Strategi Pemasaran ditingkatkan bisa menaikan Keputusan Pembelian Konsumen dan juga sebaliknya. Maka dari itu, hasil penelitian ini berhubungan pada penelitian yang diteliti Harahap (2018) tentang Pengaruh Strategi Pemasaran terhadap Keputusan Pembelian Asuransi Kendaraan Bermotor di PT Asuransi Sinarmas Cabang Garut yang menyatakan strategi pemasaran berpengaruh kuat dan positif signifikan terhadap keputusan pembelian konsumen.

Secara parsial oleh hitungan uji T terdapat pengaruh kuat dan positif signifikan pada variabel Strategi Pemasaran $\left(\mathrm{X}_{1}\right)$ terhadap variabel Keputusan Pembelian Konsumen (Y), dimana $t_{\text {hitung }}$ sebesar 4,281 $t_{\text {tabel }}$ sebesar 2,012 dan signifikan senilai 0,003 < 0,05 jadi Ho tidak diterima dan Ha dapat diterima. Dilihat dari nilai koefisien korelasi antara Pengaruh Strategi Pemasaran $\left(\mathrm{X}_{1}\right)$ terhadap variabel Keputusan Pembelian Konsumen (Y) senilai 0,701 menandakan pengaruh yang kuat sebab ada di interval $(0,600-$ 0,799).

Dari rumusan masalah yakni apakah ada pengaruh antara variabel Strategi Pemasaran $\left(\mathrm{X}_{1}\right)$ Keputusan Pembelian Konsumen (Y) serta hipotesis yakni diduga ada pengaruh antara kedua variabel tersebut dan hasil analisis diatas didapat bahwa adanya pengaruh juga pada kedua variabel tersebut maka hipotesis terbukti benar.

\section{Pengaruh Kualitas Pelayanan $\left(X_{2}\right)$ terhadap Keputusan Pembelian Konsumen (Y)}

Dari hitungan analisis regresi berganda didapat hasil koefisien $b_{2}$ yaitu 0,323 yang bernilai positif sehingga dapat diambil kesimpulan variabel Kualitas Pelayanan $\left(\mathrm{X}_{2}\right)$ mempunyai pemgaruh positif terhadap Keputusan Pembelian Konsumen (Y), maka Kualitas Pelayanan ditingkatkan maka akan menaikan
Keputusan Pembelian Konsumen juga sebaliknya. Dari hasil penelitian maka berhubungan dengan apa yang diteliti oleh Amhar (2012) tentang Pengaruh kompetensi financial advisor dengan kualitas pelayanan bank terhadap keputusan pembelian barang produk banca assurance di PT AXA Mandiri Finansial Service yang menyatakan kualitas pelayanan berdampak kual dan positif signifikan terhadap keputusan pembelian konsumen.

Secara parsial dari hitungan uji T terjadi pengaruh positif dan signifikan diantara variabel Kualitas Pelayanan $\left(\mathrm{X}_{2}\right)$ terhadap variabel Keputusan Pembelian Konsumen (Y), dimana $t_{\text {hitung }}$ sebesar 3,396 $t_{\text {tabel }}$ 2,012 dan signifikan senilai 0,001 <0,05 jadi Ho tidak diterima dan $\mathrm{Ha}$ dapat diterima. Dilihat dari nilai koefisien korelasi antara Kualitas Pelayanan $\left(\mathrm{X}_{2}\right)$ terhadap variabel Keputusan Pembelian Konsumen (Y) senilai 0,656 menandakan pengaruh yang begitu kuat sebab ada di interval $(0,600-0,799)$.

Dari rumusan masalah yakni apakah ada pengaruh antara variabel Kualitas Pelayanan $\left(\mathrm{X}_{2}\right)$ terhadap Keputusan Pembelian Konsumen (Y) serta hipotesis yakni diduga ada pengaruh antara kedua variabel tersebut dan hasil analisis diatas didapat bahwa adanya pengaruh juga pada kedua variabel tersebut maka hipotesis terbukti benar.

Pengaruh Strategi Pemasaran $\left(X_{I}\right)$ dan Kualitas Pelayanan $\left(\mathrm{X}_{2}\right)$ terhadap Keputusan Pembelian Konsumen (Y)

Berdasarkan hasil analisis regresi berganda diperoleh nilai koefisien $b_{1}$ yaitu 0,517 dan $b_{2} 0,323$ yang bernilai positif sehingga dapat diambil kesimpulan bahwa variabel Strategi Pemasaran $\left(\mathrm{X}_{1}\right)$ dengan Kualitas Pelayanan $\left(\mathrm{X}_{2}\right)$ memiliki dampak positif terhadap Keputusan Pembelian Konsumen (Y), jadi jika Strategi Pemasaran dengan Kualitas Pelayanan ditingkatkan maka akan menaikan Keputusan Pembelian Konsumen dan begitu juga sebaliknya. Dari hasil penelitian ini sesuai pada apa yang diteliti oleh Kuswaraningtyas (2017) tentang Pengaruh Produk, Harga, Promosi, Tempat dan Kualitas Pelayanan terhadap Keputusan Pembelian Pada Konsumen PT Jalur Nugraha Ekakurir yang menyatakan strategi pemasaran berdampak kuat dan positif signifikan terhadap keputusan pembelian pada konsumen.

Secara simultan berdasarkan hitungan uji $F$ terjadi dampak positif dan signifikan diantara variabel Pengaruh Strategi Pemasaran $\left(X_{1}\right)$ dan Kualitas Pelayanan $\left(\mathrm{X}_{2}\right)$ terhadap Keputusan Pembelian Konsumen (Y), dimana $F_{\text {hitung }}$ sebesar 33,508> $F_{\text {tabel }}$ sebesar 3,20 dan signifikan senilai $0,000<0,05$ jadi Ho tidak diterima dan Ha dapat diterima. Dilihat dari nilai koefisien korelasi berganda $R=770$ berarti besarnya 
pengaruh Strategi Pemasaran dan Kualitas Pelayanan terhadap Keputusan Pembelian Konsumen yaitu 0,770 dan terdapat pada interval $(0,600-0,799)$ dari hasil ini mempunyai pengaruh yang kuat, searah dan positif.

Berdasarkan rumusan masalah yakni apakah terdapat dampak pada variabel Strategi Pemasaran $\left(\mathrm{X}_{1}\right)$ dan Kualitas Pelayanan $\left(\mathrm{X}_{2}\right)$ terhadap Keputusan Pembelian Konsumen ( $\mathrm{Y}$ ) serta hipotesis yakni diduga ada pengaruh antara ketiga variabel tersebut dan hasil analisis diatas didapat bahwa adanya pengaruh juga pada ketiga variabel tersebut maka hipotesis terbukti benar.

Sedangkan kontribusi dari variabel Pengaruh Strategi Pemasaran dan Kualitas Pelayanan adalah 59,3\% yang berarti signifikan dalam Keputusan Pembelian Konsumen (Y), dan sisanya senilai $40,7 \%$ merupakan pengaruh dari faktor hal lain.

\section{KESIMPULAN DAN SARAN}

Berdasarkan keseluruhan rangkaian analisis terhadap data penelitian hasil, dapat disimpulkan secara parsial dari hitungan uji $\mathrm{T}$ terdapat dampak positif signifikan antara variabel Strategi Pemasaran $\left(\mathrm{X}_{1}\right)$ dengan variabel Keputusan Pembelian Konsumen (Y), dimana $t_{\text {hitung }}$ sebesar 4,281 $t_{\text {tabel }}$ sebesar 2,012 dan signifikan senilai $0,003<0,05$ jadi Ho tidak diterima dan Ha dapat diterima. Dilihat dari nilai koefisien korelasi antara Pengaruh Strategi Pemasaran $\left(\mathrm{X}_{1}\right)$ terhadap variabel Keputusan Pembelian Konsumen (Y) senilai 0,701 menandakan pengaruh yang positif dan kuat sebab ada di interval $(0,600-0,799)$.

Secara parsial dari hasil uji $\mathrm{T}$ terdapat pengaruh positif dan signifikan diantara variabel Kualitas Pelayanan $\left(\mathrm{X}_{2}\right)$ dengan variabel Keputusan Pembelian Konsumen $(\mathrm{Y})$, dimana $t_{\text {hitumg }}$ sebesar 3,396 $t_{\text {tabel }}$ 2,012 dan signifikan senilai $0,001<0,05$ jadi Ho tidak diterima dan Ha dapat diterima. Dilihat dari nilai koefisien korelasi antara Kualitas Pelayanan $\left(\mathrm{X}_{2}\right)$ terhadap variabel Keputusan Pembelian Konsumen (Y) senilai 0,656 menandakan pengaruh begitu kuat sebab ada pada interval $(0,600-0,799)$.

Secara simultan dari hitungan uji $\mathrm{F}$ terjadi dampak yang positif dam signifikan diantara variabel Pengaruh Strategi Pemasaran $\left(\mathrm{X}_{1}\right)$ dan Kualitas Pelayanan $\left(\mathrm{X}_{2}\right)$ pada Keputusan Pembelian Konsumen $(\mathrm{Y})$, dimana $F_{\text {hitung }}$ sebesar 33,508 $>F_{\text {tabel }}$ sebesar 3,20 dan signifikan senilai $0,000<0,05$ jadi Ho tidak diterima dan $\mathrm{Ha}$ dapat diterima. Dilihat dari nilai koefisien korelasi berganda $\mathrm{R}=770$ berarti besarnya Pengaru Strategi Pemasaran dan juga Kualitas Pelayanan pada Keputusan Pembelian Konsumen yaitu 0,770 dan terdapat di interval $(0,600-0,799)$ dari hasil ini mempunyai pengaruh yang kuat, searah dan positif.
Dari semua hasil analisis maka penulis menyarankan sebagai masukan bagi perusahaan dalam hubungan Strategi Pemasaran $\left(\mathrm{X}_{1}\right)$ dan Kualitas Pelayanan $\left(\mathrm{X}_{2}\right)$ terhadap Keputusan Pembelian Konsumen (Y). Saransaran tersebut yaitu: (1) Perusahaan dalam hal ini harus meningkatkan sosialisasi jasa diantaranya dengan pasang iklan melalui media sosial, website, serta media mainstream dan menyediakan potongan harga untuk konsumen dapat mengerti layanan apa yang dikerjakan dan juga bisa menarik konsumen agar terus menggunakan jasa PT Sarana Bandar Logistik dalam setiap kali konsumen ingin melakukan pengiriman, (2) Perusahaan dalam hal ini harus meningkatkan kualitas pelayanan dan memberikan sosialisasi terhadap para karyawan untuk terus tetap bersikap ramah dan selalu memberikan perhatian kepada konsumen yang datang supaya nyaman dan tidak kecewa atas layanan yang diberikan, dan jika masih ada karyawan yang masih kurang ramah dan perhatian terhadap konsumennya perusahaan harus berani menegur dan memberikan sanksi terhadap para karyawannya, dan (3) Perusahaan dalam hal ini diharapkan memudahkan konsumen yang berlokasi di wilayah yang cukup jauh dari kantor yang berada di Tanjung Priok, Jakarta Utara seperti membuka kantor cabang di setiap daerah di bodetabek untuk memudahkan konsumen yang berada cukup jauh dari kantor PT. Sarana Bandar Logistik sehingga dapat menarik minat konsumen yang berada cukup jauh dari Tanjung Priok agar memutuskan menggunakan PT. Sarana Bandar Logistik karena lokasi kantor penerimaan barang yang dekat dengan konsumen.

\section{DAFTAR PUSTAKA}

Amhar, F. (2012). Pengaruh Kompetensi Financial Advisor dan Kualitas Layanan Bank Terhadap Keputusan Pembelian Barang Produk Bancassurance Pada PT AXA Mandiri Finansial Service. Semarang: Universitas Diponegoro.

Assauri, S. (2013). Manajemen Pemasaran. Jakarta: Rajawali Pers.

Harahap, E. F. (2018). Pengaruh Strategi Pemasaran terhadap Keputusan Pembelian Asuransi Kendaraan Bermotor pada PT Asuransi Sinarmas Cabang Garut. Journal of Knowledge Management 12(1): 12-20.

Hurriyati, R. (2010). Bauran Pemasaran dan Loyalitas Konsumen. Bandung: CV Alfabeta.

Kotler, P and Amstrong, G. (2012). Prinsip Pemasaran. Jakarta: Erlangga.

Kotler, P and Amstrong, G. (2014). Prinsip-prinsip Manajemen. Jakarta: Erlangga.

Kotler, P and Amstrong, G. (2016). Prinsip - Prinsip Pemasaran. Jakarta: Erlangga. 
Kotler, P and Keller, K. L. (2012). Manajemen Pemasaran (Edisi 12). Jakarta: Erlangga.

Kuswaraningtyas, H. L. (2017). Pengaruh Produk, Harga, Promosi, Tempat dan Lokasi Kualitas Pelayanan Terhadap Kepuasan Konsumen Studi Kasus pada Pelanggan PT. Jalur Nugraha Ekakurir Cabang Klaten. Skripsi. Yogyakarta: Universitas Sanata Dharma.

Majid, S. A. (2015). Customer Service dalam Bisnis Jasa Transportasi. Jakarta: PT Rajagrafindo Persada.

Schiffman, L., and Kanuk, L. L. (2014). Perilaku Konsumen. Jakarta: Indeks.

Sugiyono. (2017). Metode Penelitian Kunatitatif Kualitatif dan $R \& D$. Bandung: CV Alfabeta.
Sumarwan, U. (2011). Perilaku Konsumen: Teori dan Penerapannya dalam Pemasaran. Jakarta: PT Ghalia Indonesia.

Sunyoto, D. (2015). Manajemen dan Pengembangan Sumber Daya Manusia (Cetakan Pertama). Yogyakarta: CAPS (Center for Academic Publishing Service).

Supranto, J. (2011). Pengukuran Tingkat Kepuasan Pelanggan. Jakarta: PT Rineka Cipta.

Tjiptono, F. (2010). Strategi Pemasaran. Yogyakarta: Andi offset.

Tjiptono, F. (2011). Pemasaran Jasa. Malang: Bayumedia.

Tjiptono, F dan Chandra, G. (2012). Service, Quality Satisfaction. Yogyakarta: Andi offset. 